\title{
Impact of a Continuing Education Program on Pharmacists' Knowledge and Attitudes toward Asthma Patient Care
}

\author{
Yi-Chun Chianga,d Chun-Nin Lee ${ }^{b}$ You-Mei Lin ${ }^{c}$ Yu-Hsuan Yen ${ }^{a, d}$ \\ Hsiang-Yin Chen ${ }^{a, d}$ \\ Departments of a Pharmacy and ${ }^{b}$ Internal Medicine, Taipei Medical University Wan Fang Hospital, \\ 'Department of Pharmacy, Taipei Medical University Shuang Ho Hospital, and d College of Pharmacy, \\ Taipei Medical University, Taipei, Taiwan
}

\section{Key Words}

Asthma $\cdot$ Asthma care $\cdot$ Attitude $\cdot$ Knowledge $\cdot$ Pharmacist $\cdot$ Questionnaire

\begin{abstract}
Objective: The objective of this study was to evaluate the impact of an asthma continuing education program on pharmacists' knowledge and attitudes related to asthma pharmaceutical care. Subjects and Methods: A 20-hour continuing education program was conducted by the joint efforts of the Taipei City Government, Taiwan Association of Asthma Education and Taipei Medical University Wan Fang Hospital, in a series of 4 days afternoon sessions from June 26 to July 4, 2004. One hundred and twenty-five pharmacists participated. The Asthma Knowledge Test in Mandarin and the Asthma Attitude Scale in Mandarin were developed by adapting the scale used to evaluate the impact of pharmacist continuing education programs on diabetic care. The results before and after the intervention were compared to evaluate the impact of the program. Results: Of the 125 participants, 105 returned both the pre- and post-intervention questionnaires, for a response rate of $84.0 \%$. The total score of the attitude section increased significantly from $40.04 \pm 3.35$ to $42.54 \pm 2.98$ (full score $=50, p<0.001$ ). The
\end{abstract}

total score of the knowledge section also increased significantly from $7.18 \pm 1.31$ to $7.56 \pm 1.15(p=0.008)$. Improvement in the attitude score was found in $70(67.0 \%)$ subjects, and in the knowledge score in 45 (43.5\%) subjects. Conclusion: The study demonstrated that attitude and knowledge toward asthma care improved after the continuing education program. Further study of long-term impact and direct changes in asthma pharmaceutical care practice will be necessary.

Copyright $\odot 2010$ S. Karger AG, Basel

\section{Introduction}

Competent pharmacists with positive attitude and sufficient knowledge are crucial to the outcome of pharmaceutical care for asthma patients. The asthma educator certification process was first launched in 1999 by the American Lung Association [1]. The first asthma educator certification examination was offered by the National Asthma Educator Certification Board in 2002, sixteen years after the National Certification Board for Diabetes Educators was established in the United States. In Asian countries, developments in establishing asthma pharmaceutical care were even slower. As with many countries in 
Asia, pharmacy education in Taiwan is a 4- to 5-year bachelor program, including a 4 -month internship. The undergraduate pharmacy curriculum in Taiwan contains insufficient content related to asthma care. This means that continuing education (CE) programs are essential to enhance and maintain the ability of pharmacists to provide asthma care. This is particularly important because the prevalence of asthma in Taiwan is as high as $7.79 \%$. Taiwan established its own multidisciplinary asthma educator certification organization, the Taiwan Association of Asthma Education, in 2003 [2].

The role of pharmacists in asthma management has received positive recognition worldwide [3]. A majority of publications in the past decade that have addressed the role of pharmaceutical care for asthma have reported that well-educated pharmacists could enhance the therapeutic outcomes of patients, including severity of disease, quality of life, medical resource utilization and adherence to medications [4-7]. However, some other studies [8-10] reported disappointing or modest results, even though the pharmacists involved had received education prior to administering patient care. Ineffective education which is unable to affect pharmacists' behavior has been cited as a possible cause of this phenomenon.

When the goal is to change clinical practice, the key factor in any behavior mechanism is attitude change rather than knowledge improvement [11]. Healthcare professionals must be knowledgeable in their specialty. However, the attitude of clinicians could affect the adherence of asthmatic patients [12] and further impact patient outcomes [13]. A well-designed pharmacy CE would put at least as much emphasis on measurement of attitude improvement as knowledge enhancement. The objective of this study was to evaluate the impact of an asthma CE program on pharmacists' knowledge and attitude towards asthma patient care.

\section{Subjects and Methods}

A 20-hour CE program was conducted by the joint effort of the Taipei City Government, the Taiwan Association of Asthma Education, and Taipei Medical University Wan Fang Hospital, over 4 days from June 26 to July 4, 2004. The program was held at Taipei Medical University Wan Fang Hospital. Doctors from the Taiwan Association of Asthma Education and clinical pharmacists from major medical centers in Taipei provided content development and instruction for the program. The content of the program was based on the Global Initiative for Asthma report and the World Health Organization workshop report [14]. The curriculum was composed of 3 educational models, including lectures, case studies and hands-on practice (table 1).
Program information was announced to hospital and community pharmacies in Taipei, and pharmacists were invited to attend. Pre-intervention questionnaires were distributed to all attendees of the CE program and collected before beginning the first lesson. Post-intervention questionnaires were delivered to all attendees after the last lesson ended and collected before they exited. One hundred and twenty-five registered pharmacists who returned both questionnaires were enrolled as the study population. Knowledge and attitude scores before and after the CE were compared to evaluate the efficacy of the program. This survey was exempted from institutional review board review according to the standards of Taipei Medical University Wan Fang Hospital.

\section{Questionnaire Development}

Knowledge Test. The Asthma Knowledge Test in Mandarin (AKT-M) was developed by adapting the Diabetes Knowledge Test, developed by the University of Michigan Diabetes Research and Training Center [15], and the Diabetes Knowledge Test in Mandarin [16]. The knowledge examination consisted of 10 multiple-choice questions divided into 3 categories, as shown in table 2 . Scores were calculated as the sum of correct answers, with 10 being the highest possible score.

Attitude Measures. The Asthma Attitude Scale in Mandarin (AAS-M) was designed to measure pharmacists' attitudes toward asthma by adapting concepts from the Diabetes Attitude Scale [17] and Diabetes Attitude Scale in Mandarin [16]. The questionnaire was divided into 5 categories, as shown in table 2. Each item of the questionnaire was scored on a 5-point scale. Higher scores represented a more positive attitude toward current concepts of asthma care. English versions of the questionnaires are included in the Appendix.

Validity and reliability of the AKT-M and AAS-M was ensured by a panel of experts in pulmonary care, clinical pharmacy, and experts in survey questionnaire development who validated the content of each questionnaire to assure their effectiveness in collecting the desired information. Thirty-one registered pharmacists who were not in but who had a similar background to the study population were involved in assessing the surveys' face validity to make sure the questions were able to be understood by a similar population. Test-retest reliability was assessed using the same group of pharmacists without intervention to test the stability of the measurement, resulting in Spearman correlation coefficients of 0.650 for the AAS-M and 0.820 for the AKT-M.

\section{Statistical Analyses}

Spearman's correlation was used to identify association for test and re-test reliability. The McNemar test and Wilcoxon signed-rank test were used to analyze the difference in the correct rates of knowledge and the scores of AKT-M and AAS-M. Mann-Whitney U test and Mann-Whitney $\mathrm{H}$ test were also employed to assess the association of demographic data and improvement of knowledge and attitudes. All statistical tests were computed using the Statistical Package for the Social Sciences (v. 10.0; SPSS, Chicago, Ill., USA) with significance defined as a $\mathrm{p}<0.05$.

Of the 125 participants, 105 pharmacists who returned both the pre-intervention and post-intervention questionnaires were designated the study population. The data analyses were performed on these 105 responses. The response rate was $84 \%$. 
Table 1. Time allotment for CE program

\begin{tabular}{llll}
\hline Format and topics & Content & Hours \\
\hline $\begin{array}{l}\text { Lectures } \\
\text { Asthma disease } \\
\text { Pharmacotherapy }\end{array}$ & $\begin{array}{l}\text { Introduction to the disease, conducted by 2 experienced thoracic doctors } \\
\text { Monographs and comparison of various relievers and controllers, } \\
\text { therapeutic strategies and medication selection } \\
\text { Review of principles for asthma care, function and importance of the } \\
\text { pharmacist in the asthma care }\end{array}$ & 4 \\
Specialized care & $\begin{array}{l}\text { Asthma therapy for special populations and management of acute } \\
\text { exacerbation in intensive care settings }\end{array}$ & 4 \\
\hline $\begin{array}{l}\text { Case discussion and } \\
\text { role-play activity }\end{array}$ & $\begin{array}{l}\text { Discussion of treatment plan for actual cases; practice developing } \\
\text { partnerships with patient, and identify patients' medication-related } \\
\text { needs (understanding, expectation, concerns) }\end{array}$ & 4 \\
\hline $\begin{array}{l}\text { Patient education } \\
\text { practice }\end{array}$ & $\begin{array}{l}\text { Practice using peak flow meter, inhaler operation and teaching skills, } \\
\text { and using patient education material }\end{array}$ & 2 \\
\hline Total & & 20 \\
\hline
\end{tabular}

Table 2. Knowledge and attitude: impact of CE on asthma care

\begin{tabular}{lcrrr}
\hline Categories & Items & Pre-intervention & Post-intervention & p value \\
\hline Knowledge & & & & \\
Pharmacotherapy & 4 & $2.65 \pm 0.89$ & $3.13 \pm 0.90$ & $<0.001$ \\
Pathophysiology of asthma & 2 & $1.84 \pm 0.42$ & $1.81 \pm 0.42$ & 0.686 \\
Peak flow meter and care plan & 4 & $2.60 \pm 0.83$ & $2.62 \pm 0.55$ & 0.885 \\
Total scores & 10 & $7.18 \pm 1.31$ & $7.56 \pm 1.15$ & 0.008 \\
\hline Attitude & & & & $<0.001$ \\
Specialized training & 2 & $8.94 \pm 0.99$ & $9.35 \pm 0.92$ & $<0.001$ \\
Health impact of asthma & 2 & $8.56 \pm 1.02$ & $9.01 \pm 0.86$ & 0.231 \\
Autonomy of patients & 3 & $10.45 \pm 1.64$ & $10.58 \pm 1.25$ & $<0.001$ \\
Value of close monitoring & 2 & $7.64 \pm 1.44$ & $9.02 \pm 1.05$ & 0.005 \\
Role of pharmacist on asthma care & 1 & $4.43 \pm 0.55$ & $4.58 \pm 0.62$ & $<0.001$ \\
Total scores & 10 & $40.04 \pm 3.35$ & $42.54 \pm 2.98$ & \\
\hline
\end{tabular}

\section{Results}

The demographics of the pharmacists are shown in table 3. The pharmacists in the study group were practicing in a broad variety of settings. The CE program significantly improved pharmacists' knowledge of asthma care, with a total AKT-M score increase from $7.18 \pm 1.31$ to $7.56 \pm 1.15(\mathrm{p}=0.008)$. The score in the subscale of asthma pharmacotherapy improved from $2.65 \pm 0.89$ to $3.13 \pm 0.90$ (full score $=4, \mathrm{p}<0.001$; table 2 ). The baseline knowledge scores in the subscales for the pathophys- iology of asthma as well as the peak flow meter and care plan were already high. Therefore, both scores did not increase significantly after the CE program (table 2). Only 45 (43.5\%) pharmacists showed improvement in knowledge.

The pre- and post-intervention AAS-M attitude scores improved significantly by 2.5 points from 40.04 \pm 3.35 to $42.54 \pm 2.98$ (full score $=50, \mathrm{p}<0.001$; table 2). The subsets attitude scores of the importance of specialized training, the health impact of asthma disease, the value of close monitoring, and the role of the 
Table 3. Demographic data of enrolled pharmacists

\begin{tabular}{lc}
\hline Demographic characters & Number $(\%)$ \\
\hline Type of pharmacy $(\mathrm{n}=105)$ & \\
Hospital pharmacy & $58(55.2)$ \\
Retail pharmacy & $36(34.3)$ \\
Clinic pharmacy & $11(10.5)$ \\
Gender $(\mathrm{n}=105)$ & \\
Male & $27(25.7)$ \\
Female & $78(74.3)$ \\
Education level $(\mathrm{n}=105)$ & $28(26.7)$ \\
Master degree or above & $57(54.3)$ \\
Bachelor degree & $20(19.0)$ \\
College technical school & \\
Graduate year $(\mathrm{n}=105)$ & $6(5.7)$ \\
Before 1971 & $15(14.3)$ \\
1971-1980 & $24(22.9)$ \\
1981-1990 & $60(57.1)$ \\
After 1990 & $4(3.8)$ \\
With asthma history $(\mathrm{n}=104)$ & $20(19.2)$ \\
With asthma family history $(\mathrm{n}=104)$ &
\end{tabular}

${ }^{a}$ Clinic pharmacies are private pharmacies sponsored by a physician owner.

pharmacist in asthma care showed significant improvement after the CE program. Only the autonomy subscale failed to show significant improvement (10.45 \pm 1.64 vs. $10.58 \pm 1.25$, full score $=15, \mathrm{p}=0.231$ ). The mean total scores on the AAS-M and on each of the 6 subscales exceeded the neutral point of 3 , which indicated positive attitudes toward current concepts of asthma care. Improvement in attitude scores was shown in $70(67.0 \%)$ pharmacists.

Subgroup analyses of gender, service setting, year of graduation and educational level, formed to identify the influence of demographic characteristics on the differences of AKT-M and AAS-M before and after the intervention, showed no significant difference ( $p$ value for knowledge ranged from 0.064 to 0.698 while that of attitude from 0.469 to 0.86 ). The baseline knowledge scores were slightly higher in the asthmatic group than in the non-asthmatic group $(6.64 \pm 1.36$ and $6.27 \pm 1.22$, respectively,) but the difference was not statistically significant $(\mathrm{p}=0.495)$. No difference between groups was found in the AAS-M scores. The variations of knowledge and attitude had only intermediate correlation with a Spearman's rho correlation coefficient of 0.046 , and $\mathrm{p}=$ 0.714 .

\section{Discussion}

The result of our study on CE with validated, reliable and constructive measurement of knowledge and attitude, AKT-M and AAS-M, showed that CE towards asthma care can improve the knowledge and attitude of pharmacists as reported for nurses and physicians $[18,19]$. The pharmacists were trained to have sufficient knowledge and skills, and positive attitude for asthma patient education. Our study confirmed that well-trained pharmacists can provide more effective patient education, improve patient knowledge, and encourage proper inhaler technique as previously reported [20].

The CE program in this study was designed to anchor each concept by implementing hands-on practice in operating metered-dose inhalers, dry-powder inhalers, and peak flow meters, in addition to lectures to make the training relevant to pharmacy practice [21, 22]. This method was in keeping with the results of a Canadian CE that linked hands-on practice and coaching in inhaler technique to greater improvement in knowledge than simply providing written materials [23]. The pharmacists subjectively experienced the difficulties of inhaler operation and became familiar with adverse effects of asthma medicines.

Of paramount interest in this current study was the attitude of pharmacists towards patient autonomy. As pharmaceutical care is patient-centered, patients should participate to increase their partnership and responsibility, consequently improving their adherence to long-term medication therapies [24]. However, 83 (79\%) pharmacists in our study did not change their attitude toward allowing the asthmatic patient the authority to decide whether not to take care of his/her own illness. This finding may be due to the life-threatening consequences of asthma exacerbation, and includes ethical debate about the mission of healthcare providers to save lives [25]. Another possible explanation may be the lack of patient involvement, such as expert/standardized patients or consumer educators, in the program [26, 27]. Involving the patient in the education program is worth considering as it may affect pharmacists' attitudes toward patient autonomy [28].

The most significant limitation of this study was its short-term design. Thus, no behavior or practice impacts were evaluated. A previous study of asthma CE for physicians showed a significant improvement in physicians' prescription habits and patient education [29]. Another limitation was the response rate. A lack of data from $16 \%$ of pharmacists, although relatively low in 
comparison with reference surveys [15-17], could affect the results by producing a tendency toward smaller difference. Further large-scale studies that aim to assess changes in clinical practice and patient perception, along with greater control over response rate, will be necessary to evaluate the long-term effects of asthma CE for pharmacists.

\section{Conclusion}

This study demonstrated significant improvements in knowledge and attitude among pharmacists who attended the CE program. The questionnaire, which was designed for the purpose of this study, is the first validated, reliable and constructive questionnaire in Mandarin, and could be used in other Mandarin-speaking countries to evaluate the knowledge and attitude of pharmacists toward asthma care.

\section{Appendix}

Asthma Knowledge Test in Mandarin (AKT-M) and Asthma Attitude Scale in Mandarin (AAS-M)

$\begin{array}{llll}\text { Institute } & \square \text { Hospital } & \square \text { Community pharmacy } & \square \text { Clinics } \\ \text { Gender } & \square \text { Male } & \square \text { Female } & \\ \text { Education } & \square \text { Post-graduate } & \square \text { University } & \square \text { Specialist } \\ \text { Year of graduation } & \square \text { Before 1971 } & \square \text { 1971-1980 } & \square \text { 1981-1991 } \\ \text { Are you an asthma patient? } & & \square \text { After 1991 } \\ \text { Do you have relatives that are asthmatic patients? } & & \square \text { Yes } & \square \text { No }\end{array}$

Part 1. Please mark the response that best expresses your opinion

In general, I believe that

1 Healthcare providers should understand the influence of asthma care activities on patients' daily lives.

2 Pharmacists should be certified to provide primary asthma care.

3 The impact of asthma on patients' emotions is minor.

4 To become a competent asthma educator, it is necessary to learn education skills.

5 The outcome of asthma treatment depends more on a patient's behavior than efforts of healthcare providers.

6 Asthmatic patients may not benefit from disease monitoring with peak flow meter.

7 Control of respiration function is too complicated in asthma care.

8 People with asthma have the right to decide not to take care of their disease.

9 The asthmatic patient is the most important member in the asthma care team.

10 The pharmacist could play an important role in the asthma care team. 
Part 2. Choose the most adequate answer

1 Among the following physiological factors, which could affect theophylline blood concentration the most?

$\square$ Abnormal liver function $\square$ Induced liver enzyme $\square$ All of above $\square$ None of above

2 Which of the following could be a side effect of inhaled steroids?

$\square$ Reduce bone density $\square$ Skin thinning $\square$ Glaucoma $\square$ Cataracts $\square$ All of above

3 Which of the following ranges characterizes the 'yellow zone' for peak flow meter measurements? $80 \% \square 60-80 \% \square 30-60 \% \square<20 \%$

4 Poor asthma control may be related to:

$\square$ Poor inhaler technique $\square$ Low or non-adherence to therapy $\square$ Uncontrolled environmental factors $\square$ All of above

5 Which of the following is considered the cell that triggers an allergic reaction after exposure to the allergen?

$\square$ Eosinophil $\square$ Neutrophil $\square$ Mast cell $\square$ Platelet

6 What is the best time to use a peak flow meter, if the patient can use it only once daily?

$\square$ After waking up, before going out in the morning $\square$ After using bronchodilators

$\square$ Before using bronchodilators $\square$ Before sleep at night

7 Which of the following has nothing to do with an inflammation reaction?

$\square$ Histamine $\square$ Prostaglandins $\square$ Leukotriene $\square$ Epinephrine

8 Which one of the following is not a sympathomimetic drug, administered as aerosol, and could dilate the bronchioles with fewer systemic side effects?

$\square$ Salmeterol $\square$ Atropine $\square$ Isoproterenol $\square$ Ipratropium bromide $\square$ Albuterol

9 Long-term asthma control for children with moderate continuous asthma should include which of the following drugs?

$\square$ Cromolyn, salmeterol and albuterol

$\square$ Beclomethasone, salmeterol and albuterol

$\square$ Zafirlukast, triamcinolone and albuterol

$\square$ Zileuton, flunisolide and albuterol

10 Which statement is true about short-acting $\beta_{2}$-agonists?

$\square$ It is the most efficient drug to relieve bronchial smooth-muscle spasms in acute attacks

$\square$ The more it is used, the worse the asthma is controlled

$\square$ It should be used when needed, and does not require routine dose

All of above

\section{References}

1 NAECB, National Asthma Educator Certification Board, San Antonio, 2005. www. naecb.org/about/history.htm

2 TAAE, Taiwan Association of Asthma Education, Taipei. www.asthma-edu.org.tw/ asthma/ (in Chinese).

- 3 Benavides S, Rodriguez JC, ManiscalcoFeichtl M: Pharmacist involvement in improving asthma outcomes in various healthcare settings: 1997 to present. Ann Pharmacother 2009;43:85-97.

-4 Narhi U, Ariaksinen M, Tanskanen P, Erlund $\mathrm{H}$ : Therapeutic outcomes monitoring by community pharmacists for improving clinical outcomes in asthma. J Clin Pharm Ther 2000;25:177-183.
5 Herborg H, Soendergaard B, Froekjaer B, Fonnesbaek L, Jorgensen T, Hepler CD, Grainger-Rousseau TJ, Ersboell BK: Improving drug therapy for patients with asthma. Part 1. Patient outcomes. J Am Pharm Assoc 2001;41:539-550.

-6 Stiegler KA, Yunker NS, Crouch MA: Effect of pharmacist counseling in patients hospitalized with acute exacerbation of asthma. Am J Health Syst Pharm 2003;60:473-476.

-7 Armour C, Bosnic-Anticevich S, Brillant M, Burton D, Emmerton L, Krass I, Saini B, Smith L, Stewart K: Pharmacy asthma care program (PACP) improves outcomes for patients in the community. Thorax 2007;62: 496-502.
Stergachis A, Gardner JS, Anderson MT, Sullivan SD: Improving pediatric asthma outcomes in the community setting: does pharmaceutical care make a difference? J Am Pharm Assoc 2002;42:743-752.

9 Emmerton L, Shaw J, Kheir N: Asthma management by New Zealand pharmacists: a pharmaceutical care demonstration project. J Clin Pharm Ther 2003;28:395-402.

10 Rouleau R, Beauchesne MF, Laurier C: Impact of a continuing education program on community pharmacists' interventions and asthma medication use: a pilot study. Ann Pharmacother 2007;41:574-580.

11 Ajzen I: Nature and operation of attitudes Annu Rev Psychol 2001;52:27-58. 
12 Bender BG: Overcoming barriers to nonadherence in asthma treatment. J Allergy Clin Immunol 2002;109:S554-S559.

13 Clark NM, Gong M, Schork MA, Evans D, Roloff D, Hurwitz M, Maiman L, Mellins RB: Impact of education for physicians on patient outcomes. Pediatrics 1998;101:831836.

14 GINA Science Committee GEC: Global Strategy for Asthma Management and Prevention. Global Initiative for Asthma, 2004. www.ginasthma.org/Guidelineitem.asp?? $11=2 \& 12=1 \&$ int $I d=1561$

15 Fitzgerald JT, Funnell MM, Hess GE, Barr PA, Anderson RM, Hiss RG, Davis WK: The reliability and validity of a brief diabetes knowledge test. Diabetes Care 1998;21:706710.

16 Chen HY, Lee TY, Huang WT, Chang CJ, Chen CM: The short-term impact of a continuing education program on pharmacists' knowledge and attitudes toward diabetes in Taiwan. Am J Pharm Educ 2004;68:1-6.

-17 Anderson RM, Fitzgerald JT, Funnell MM, Gruppen LD: The third version of the diabetes attitude scale. Diabetes Care 1998;21: 1403-1407.
18 Rovithis E, Lionis C, Schiza SE, Bouros D, Karokis A, Vlachonikolis I, Siafakas NM: Assessing the knowledge of bronchial asthma among primary health care physicians in Crete: a pre- and post-test following an educational course. BMC Med Educ 2001;1:2.

19 Winkelstein ML, Quartey R, Pham L, LewisBoyer L, Lewis C, Hill K, Butz A: Asthma education for rural school nurses: resources, barriers, and outcomes. J Sch Nurs 2006;22: 170-177.

20 Kritikos V, Armour CL, Bosnic-Anticevich SZ: Interactive small-group asthma education in the community pharmacy setting: a pilot study. J Asthma 2007;44:57-64.

21 Saini B, Smith L, Armour C, Krass I: An educational intervention to train community pharmacists in providing specialized asthma care. Am J Pharm Educ 2006;70:118.

22 Basheti IA, Armour CL, Bosnic-Anticevich SZ, Reddel HK: Evaluation of a novel educational strategy, including inhaler-based reminder labels, to improve asthma inhaler technique. Patient Educ Couns 2008;72:2633.

23 Jackevicius CA, Chapman KR: Inhaler education for hospital-based pharmacists: how much is required? Can Respir J 1999;6:237244.
24 Laine C, Davidoff F: Patient-centered medicine: a professional evolution. JAMA 1996; 275:152-156.

25 Quill TE, Brody H: Physician recommendations and patient autonomy: finding a balance between physician power and patient choice. Ann Intern Med 1996;125:763-769.

26 Bell JS, Whitehead P, Aslani P, Sacker S, Chen TF: Design and implementation of an educational partnership between community pharmacists and consumer educators in mental health care. Am J Pharm Educ 2006; $70: 28$.

27 Seung KJ, Bitalabeho A, Buzaalirwa LE, Diggle E, Downing M, Bhatt Shah M, Tumwebaze B, Gove S: Standardized patients for HIV/AIDS training in resource-poor settings: the expert patient-trainer. Acad Med 2008;83:1204-1209.

28 Greenhalgh T: Patient and public involvement in chronic illness: beyond the expert patient. BMJ 2009;338:b49.

29 Clark NM, Gong M, Schork MA, Kaciroti N, Evans D, Roloff D, Hurwitz M, Maiman LA, Mellins RB: Long-term effects of asthma education for physicians on patient satisfaction and use of health services. Eur Respir J 2000; $16: 15-21$. 